\title{
SENTIDO DA VIDA E VALOR DA VIDA: UMA DIFERENÇA CRUCIAL
}

\author{
Julio Cabrera \\ U niversidade de Brasília \\ kabra@unb.br
}

Resumo: N este trabalho, vou sustentar que perguntar pelo sentido da vida (humana) não é o mesmo que perguntar pelo seu valor; que freqüentemente estas duas questões se confundem; que ambas as questões têm respostas claras; que, para ser respondidas, elas devem colocar-se numa dupla dimensão, habitualmente ignorada pelos filósofos de ten dência analítica: o sentido ou valor da vida mesma, e o sentido ou valor do que acontece dentro da vida. Sustentarei que não reconhecer essa dupla dimensão prejudica os tratamentos analíticos usuais da questão do "sentido da vida".

Palavras-chave: Sentido da vida, Valor da vida, Filosofia Analítica, M oral.

Inicialmente, entendo que fornecemos o sentido de algo quando damos subsídios para a sua inteligibilidade. Por exemplo, fornecemos o sentido de uma proposição como "W ittgenstein escreveu o Tractatus antes de 1900" quando dizemos acerca de quem ela fala, o que é que ela predica dessa pessoa, o que podemos entender quando a escutamos, quando mostramos que ela não é incoerente ou absurda, que pode ser analisada com respeito às suas condições de verdade, que pode ser declarada verdadeira ou falsa etc. Fornecemos o sentido de, por exemplo, uma ação humana (como lançar-se num rio e tirar uma outra pessoa de lá), quando tentamos explicar o que essa ação significa, quando dizemos quem é o sujeito da ação, o que foi que essa pessoa fez, o que podemos entender quando assistimos a uma ação como essa, quando 
mostramos que não foi uma ação absurda (pois vimos anteriormente uma outra pessoa caindo etc.), que ela pode ser analisada com respeito às suas condições de legitimidade (moral), e que pode ser declarada corajosa, temerária, inócua etc. Por fim, fornecemos o sentido de uma obra de arte, por exemplo, de um filme, quando tentamos explicar o que é que essa obra significa, quando dizemos qual é a sua trama, seu assunto, o que é que esse filme desenvolve, o que podemos enten der quando o assistimos, quando mostramos que tem uma inteligibilidade (apesar de sua primeira aparência ser absurda ou desconexa, como, por exemplo, nos filmes de Jean-Luc Godard), e que essa obra pode ser analisada com respeito às suas condições de aceitabilidade estética, podendo ser considerada lograda, fracassada, mal dirigida etc.

Em todos estes casos, o sentido parece ser algo distinguível da determinação de algum tipo de valor: valor de verdade, no caso das proposições, valor moral, no caso de ações, valor estético no caso das obras de arte. 0 próprio sentido dessas coisas pode ser entendido como o conjunto de suas condições de valor, de qualquer tipo que seja. Parece, pois, relevante, distinguir "sentido" de "valor". 0 século XX nos acostumou, entretanto, com a idéia cética de não existirem descrições isentas de val or, de sempre projetarmos val ores nas nossas descrições, estando estas sempre como que "impregnadas" de acentuações e preferências. Isto significaria afirmar que não se pode dizer que a proposição "W ittgenstein escreveu o Tractatus antes de 1900" é acerca de W ittgenstein e do Tractatus, sem já dizer que a proposição é falsa; ou que não se pode dizer que uma pessoa jogouse na água e tirou uma outra pessoa de lá sem já afirmar que se trata de uma ação desinteressada ou egoísta, e assim por diante. Como essa postura parece-me estar longe de ser evidente, suporei que sentido e valor são coisas diferenciáveis, não de maneira totalmente nítida e definitiva, mas, pelo menos, metodologicamente. $^{1}$

A distinção, sobretudo, me parece importante no caso particular da questão do "sentido da vida (humana)", 2 precisamente 
por ser aquela mais problemática do que nos outros casos mencionados. Vamos supor que não assumimos qualquer atitude cética inicial acerca da própria procedência da questão do sentido da vida. ${ }^{3}$ Diríamos então, como base para o anteriormente esclarecido, que fornecemos o sentido de uma vida humana quando explicamos, ou tentamos explicar, quais são os el ementos estruturais e eventuais de toda e qualquer vida humana; quando fornecemos uma descrição da con dição humana básica na qual todos os homens estão inseridos, assim como as possibilidades humanas no tocante a perspectivas, intencionalidades, ações e reações, o comportamento dos seres acerca de cuja vida estamos nos perguntando, como esses seres estão constituídos, como eles são, como vivem; ao assistir como decorre uma vida humana, o que podemos entender quando assistimos a certas vidas humanas com respeito aos fins e propósitos que essas vidas se colocam; quando mostramos que as ações desses seres são, em geral, intencionais e podem ser esclarecidas mediante análise, que elas não são absurdas; e, enfim, quando fornecemos elementos para formular as condições de legitimidade de uma vida humana para decidir, em algum momento, se foi uma vida proveitosa, tensa, calma, descontraída, indiferente, frustrada, autêntica ou mesquinha, ou seja, para decidir acerca de seu valor.

A tese cética diria, neste ponto, que não é possível descrever de maneira isenta o sentido de uma vida humana sem já atribuirIhe valores. N este caso, à primeira vista, a crítica até que pareceria mais procedente, dada a peculiaridade do objeto em questão. A final de contas, vidas humanas não são proposições. $M$ as tentarei, nas seções seguintes, convencer o leitor da relevância de fazer-se a distinção também neste caso, com todos os problemas e limitações que o cercam. ${ }^{4}$

2 Sentido como valor: In CONVEnIENTES de UMa IDENTIFICAÇÃo

Q uando se pergunta pelo "sentido da vida", muito freqüentemente, os autores, tanto os analíticos quanto um escritor como 
Camus, por exemplo, passam insensivelmente do plano do sentido para o plano do valor, nas acepções que dei antes a esses termos. Entretanto perguntar pelo "sentido" não significa indagar por al go como a situação em que os homens se encontram no mundo, mas indagar qual o sentido de eles estarem aqui, de virem ao mundo, de viverem e de morrerem etc. "Sentido" não quer dizer aqui, simplesmente, inteligibilidade, mas al go vinculado com a satisfação de nossos desejos de felicidade, realização pessoal e imortalidade. $N$ ão se trata apenas de explicar como é o mundo onde o homem está, mas também como ele poderia sentir-se gratificado pelo que faz, como poderia atingir a felicidade, como poderia sentir que sua vida não fora inútil etc. Sustento que todas essas questões estão vinculadas já não mais com o sentido, mas com o valor da vida humana. ${ }^{5}$

Com efeito, antes tentei mostrar que sentido evalor são coisas diferentes. Mas, em muitos textos da tradição analítica, sentido e valor da vida humana se aproximam ao extremo, por exemplo, quando se pergunta pelo sentido de uma vida com sofrimento, pelo "sentido da dor" etc. ${ }^{6}$ Podemos perfeitamente explicar por que existem doenças, por que seres como os humanos estão fortemente afetados por elas; podemos obter uma plena inteligibilidade acerca de por que e como surge o sofrimento na vida humana etc., isto é, estritamente, explicar o sentido do sofrimento, na minha acepção. Pelo contrário, quando se perguntam coisas como "Para que nascemos se temos de sofrer?", ou se fazem afirmações como "O sofrimento tira o sentido da vida", "Sofrer tanto assim é absurdo" etc., na verdade já estão sendo colocadas questões - plenamente significativas! - a respeito do valor de uma vida humana com sofrimento, e não, estritamente, questões a respeito do sentido da vida.

Sentido e valor da vida são coisas crucialmente diferentes, e seria prejudicial confundi-las, o que se mostra no fato de uma dessas instâncias poder estar presente sem que a outra o esteja. U ma vida humana pode ter sentido, mas não ter valor: uma vida humana 
pode ser mesquinha e cruel, como a vida de H itler, e ser considerada sem valor moral, porém, com seu sentido perfeitamente explicado, no que diz respeito a propósitos, fins e intenções - tal como John Toland, por exemplo, tentou mostrar em seu livro sobre Hitler. $\mathrm{N}$ esse caso, a vida de $\mathrm{H}$ itler tem pleno sentido, tanto quanto a vida de $\mathrm{G}$ andhi. Ela não é absurda. O u seja, podemos ter plena inteligibilidade de al go que consideramos monstruoso; muitas vezes podemos entender sem dar valor. 0 caso contrário também se dá: poderíamos, às vezes, ficar saben do que certas pessoas se sacrificaram por outras e dar um grande valor ao que fizeram, sem sermos capazes, por razões culturais, por exemplo, de enten der as suas ações, ou seja, de captar seu sentido. M uitas vezes admiramos sem entender. E os outros dois casos, também, são logicamente possíveis: conseguimos ambas as coisas - como no caso de Churchill ou de Che G uevara, cujas ações podemos entender e admirar - ou não conseguimos nenhuma delas. ${ }^{7}$

Entendo que seja, pois, conveniente manter esses dois conceitos (sentido e valor) distintos, apesar de vinculados, quando fal amos acerca da vida humana. Não parece conveniente identificar a estrutura de algo (que sempre se pode descrever) com as suas condições de val or. Sustentarei no que segue que, apesar de sempre podermos, em princípio, entender o sentido da vida humana (num sentido que será explicado), isso não significa ainda atribuir-the um valor. $\mathrm{O}$ u seja, pretendo, contra a tese cética, despojar de valorações o termo "sentido" quando aplicado à vida humana.

\section{SEnTido da Vida humana}

Filósofos e pessoas em geral, quando se perguntam pelo "sentido" da vida humana, fazem a in dagação acerca da vida humana em geral, de qualquer vida humana. Pergunta-se não pelos propósitos particulares de certas vidas, mas pelo propósito geral da vida humana sobre a Terra, ou no U niverso. C omo muitos autores, acredito que essa questão só tenha plena procedência para as 
abordagens chamadas teístas, ${ }^{8}$ que acreditam em certo ser transcendente que criou o mundo com al gum propósito. À luz dessa crença, é perfeitamente legítimo colocar-se a questão de qual foi o propósito último que esse ser transcendente deu ao mundo por ele criado. Eu, como muitos outros filósofos, não acho que tenhamos direito a acreditar que tal ser transcendente exista, de maneira que, após a queda dos referenciais metafísico-religiosos do passado, não se pode mais perguntar pelo sentido da vida com relação ao propósito último que tal ser teria dado ao mundo. Seria ainda plausível colocar-se 0 problema do sentido da vida humana em geral mesmo não aceitando a existência de um ser transcendente? Poder-se-ia, nesse caso, perguntar por algo assim como uma explicação natural - em termos causais ou outros - do surgimento da vida humana no U niverso, e na Terra em particular. Algo que fornecesse uma espécie de "finalidade natural" última e geral para esse tipo de vida, por exemplo, em termos da teoria da evolução. 0 homem seria um experimento de transição nessa imensa busca de milhões e milhões de séculos, o que daria à vida humana em geral o sentido de estar inserido dentro dessa cadeia. Assim, pareceria que, quando se perguntasse pelo sentido da vida humana em geral, deveríamos aceitar al gum propósito cósmico, seja dado por um ser transcendente ou por algum traço geral da natureza.

Seguindo a minha anterior linha de raciocínio, eu vejo a possi bilidade de decidir essa questão do "sentido" nas duas seguintes alternativas:

(a) Se perguntarmos pelo sentido das ações humanas na vida, como norteadas por propósitos, fins etc., o sentido de uma vida humana é algo que sempre pode ser, em princípio, fornecido, na acepção antes apresentada (seção 1). Podemos entender o sentido de ações humanas intencionais inseridas dentro de uma condição específica (de finitude etc.) em que os homens se encontram. C laro que pode acontecer que não consigamos entender ações ou intenções, mas esse entendimento é, em princípio, possível, se nos são dados os elementos culturais para tanto - por exemplo, para entender 
o sentido das ações dos muçulmanos. Cada vida humana pode ser analisada no tocante a seu sentido ou à sua falta de sentido, e podemos ser mais ou menos bem ou mal sucedidos na captação desse sentido.

(b) Se perguntarmos pelo sentido da vida humana em geral, creio que essa questão apenas tenha sentido para o ponto de vista teísta - que pode, perfeitamente, ser assumido, embora eu não 0 assuma aqui - ou para um ponto de vista que acredite em al guma finalidade natural dada pela teoria da evolução ou por alguma outra teoria científica. (D ado que uma teoria natural do sentido geral da vida não está atualmente disponível, as crenças nessa finalidade natural são tão difusas e injustificadas quanto as crenças teístas.) A pergunta pelo sentido precisa de algum parâmetro, de tal maneira que ações e intenções humanas só podem ter sentido ou não em referência a eles, sendo total mente natural que esse sentido se perca quando nos afastamos dos parâmetros - como nos acontece quando estudamos cosmologia, ou quando assistimos a um filme como 2001, uma odisséia no espaço, de Stanley Kubrik.

Essas duas alternativas esgotam, na minha perspectiva, 0 problema do "sentido da vida". Penso que todas as outras problemáticas colocadas utilizando-se a expressão "sentido da vida" - e outras como "absurdo", "sem sentido" etc. - referem-se, na verdade, ao valor da vida humana, acerca do qual, sim, eu tenho muito a dizer.

Mas, neste preciso ponto da minha reflexão, já estou em condições de introduzir o que denomino duas dimensões do perguntar pelo sentido e pelo valor da vida humana. $\mathrm{N}$ a verdade, não estou introduzindo uma diferença, mas captando-a já na distinção feita pelos filósofos - não apenas pelos teístas! - quando distinguem entre o sentido de cada vida humana em particular e 0 sentido da vida em geral. Muitos admitem que, mesmo que não sejamos capazes, sem assumir crenças religiosas, de dar um sentido à vida em geral, à vida "em si mesma", sempre podemos fornecer um sentido para nossas vidas particulares, para esta ou para aquela 
vida, dentro de certos parâmetros. Muitos deles, inclusive, acham, como foi mencionado, que a pergunta pelo sentido da vida em si mesma, em seu ser, carece de sentido, por não se utilizar de um parâmetro racionalmente inteligível. ${ }^{9}$ Veja, por exemplo: "These people mistakenly conclude that there can be no purpose in life because there is no purpose of life [... ]."10 "They naturally assume that this life or that can have meaning only if life as such has meaning." "11 A diferença é, pois, entre o sentido na vida e o sentido da vida, entre sentidos intramundanos e o sentido do próprio mundo, entre o sentido de vidas e o sentido da vida. Essa diferença pode considerar-se como uma versão fraca da diferença ontológica entre ser e ente, em termos aproximadamente heideggerianos. Sustento que ela é feita também na tradição analítica, mas sem suficiente tematização, o que limita consideravelmente as análises feitas por essa tradição sobre questões existenciais. Eu penso que essa diferença é crucial, mas considero que, no plano da pergunta pelo sentido, ela não é tão frutífera, como veremos, quanto no plano da questão do valor. ${ }^{12}$

Resumindo a presente seção, sustento que a pergunta pelo sentido do ser da vida humana tem procedência apenas no contexto religioso ou metafísico-natural, antes explicado; e que a pergunta pelo sentido das vidas humanas, ou seja, das vidas dos seres (ou dos entes) humanos pode sempre, pelo menos em princípio, ser respondida em termos intramundanos (quanto aos propósitos e fins determinados).

\section{VALOR DA VIDA E VALOR DE VIDAS}

Esta é a parte da reflexão à qual eu tenho dedicado mais atenção em meus estudos ético-metafísicos negativos. ${ }^{13}$ Penso que instalando-nos claramente no plano da pergunta pelo valor da vida humana, sem mais confundi-lo com o da pergunta pelo sentido, a diferença ser/ ente, mundano/ intramundo é crucial. A pergunta pelo valor da vida humana deveria cindir-se em duas: a pergunta 
pelo valor do ser mesmo da vida humana e a pergunta pelo valor dos entes que vivem. Assim como antes se admitia que vidas podiam ter sentido ainda que a vida mesma não o tivesse, abre-se agora a possibilidade de vidas terem valor sem que a vida mesma o tenha. M as enquanto a pergunta pelo sentido do ser mesmo da vida me parecia ter procedência apenas para posições teístas e metafísicas, a pergunta pelo valor do ser mesmo da vida me parece ter plena procedência filosófica. Vou tentar explicar por quê.

Aqui eu entendo a questão do valor nas duas dimensões kantianas: valor sensível da vida humana, referente a agrado, felicidade etc., e valor moral da vida humana, referente a dignidade, dever etc. Acredito que, diferentemente do sentido, que se movimenta no plano da pura inteligibilidade, 0 valor, em suas duas dimensões, se movimenta num plano de impacto, de afeção, num plano existencial-vivido que comovea vida humana de uma maneira que a questão do sentido - como foi entendido, ou seja, ligado à pura inteligibilidade - não comove. Com efeito, já no plano cotidiano, podemos ficar profundamente preocupados quando al guém próximo a nós nos declara que "perdeu o sentido de sua vida", por não saber mais aonde ir, o que fazer, que curso dar à sua vida, à sua profissão etc. $M$ as ficamos tremendamente angustiados quando alguém próximo a nós, ou alguma outra pessoa, nos informa que levou um tiro, que está com câncer, que foi torturado pela polícia, ou que foi preso por um crime que não cometeu, ou seja, questões todas ligadas com o valor sensível ou moral da vida. Aqui, a preocupação não é suficiente; sentimos que a pessoa que nos interessa está sofrendo, foi atingida por uma espécie de raio. N ão se trata apenas da fleumática e serena pergunta pelo sentido, mas de algo vinculado à maneira como a vida está sendo tratada e valorizada, sensível e/ ou moralmente.

É precisamente em virtude dessa característica de impacto vital - sensível ou moral - do valor que a pergunta pelo valor do ser mesmo da vida não tem o caráter metafísico-teísta da pergunta pelo sentido do ser mesmo da vida, mas uma acepção muito concreta, 
filosoficamente inteligível e empiricamente analisável. Perguntarse pelo sentido do ser mesmo da vida implica, como vimos, perguntar-se por algum tipo de plano divino do mundo, ou de estrutura natural finalista. M as perguntar-se pelo valor do ser mesmo da vida implica perguntar-se se éou não valioso, em termos sensíveis ou morais, ter surgido no mundo, ter um ser, ou uma vida, com indepen dência dos conteúdos con cretos que essa vida possa conter - ou seja, dos el ementos intramundanos de cada vida em particular. Tentemos entender isto melhor.

Podemos entender que todas as vidas humanas têm uma estrutura estável, consistente, pelo menos, nos seguintes cinco elementos: (A) U m nascimento mortal, ou seja, um surgimento signado pela terminalidade ou pela mortalidade de seu ser, um surgimento que carrega em si seu próprio finar. (B) U m desenvolvimento que consiste em um desgaste progressivo, físico e mental, ao longo de um tempo indefinido. Esse desenvolvimento pode, a qualquer momento, ser interrompido por acidente, sem que se complete. (C) U m estar sujeito a muitos tipos de doenças (os dicionários especializados contam mais de mil, com todas as suas variedades) que podem finar a vida humana já no nascimento, ou na infância, na juventude, na idade adulta ou na velhice. (D) U ma morte pontual, por desenvolvimento progressivo ou por acidente (à qual deveríamos acrescentar a possibilidade aberta de a vida humana decidir acabar com ela mesma), que consuma a mortalidade já dada no nascimento. (E) U m espaço intramundano onde se está plenamente consciente detodos os elementos anteriores (do próprio nascimento mortal, do desenvolvimento definhante, da suscetibilidade a doenças e à dor e da morte pontual consumadora), espaço onde os seres humanos deverão "posicionar-se" ou "tomar uma atitude" diante de (A)-(E). ${ }^{14}$ Importante se faz notar que é precisamente a cláusula ( $E$ ) a que distingue a vida humana da vida em geral, que parece igualmente afetada - deixando fora a possibilidade do suicídio - por todas as outras características. 
O s itens (A)-(E) constituem uma estrutura do ser mesmo da vida humana no sentido de que, sejam quaisforem as vidas concretas "levadas adiante", sejam quais forem suas opções e conteúdos, qualquer vida humana terá, monotonamente, as características (A)(E). Poderíamos dizer que a estrutura (A)-(E) é parte do que sabemos (pelo menos a parte rel evante para a questão do valor da vida) sobre a vida de alguém antes de ele nascer. As diferenças entre vidas humanas não aparecerão nas características (A)-(E), mas nos diversos tipos de equilíbrio entre mundo e intramundo, entre ser e ente desde o suicídio ea loucura atéa construção de uma "vida produtiva".

O ra, parece ter pleno sentido filosófico indagar-se pelo valor - sensível e moral - dessa estrutura, como al go diferente do indagarse pelo valor do que acontece nas vidas particulares, que ocorrem sempre sobre o pano de fundo dessa estrutura. Pessoas com a mesma estrutura (A)-(E) podem ser intramundanamente felizes e realizadas ou infelizes e frustradas. $\mathrm{O}$ sfilósofos analíticos, como Thomas $\mathrm{N}$ agel e todos os filósofos estudados por M etz e Klemke, não tematizam a diferença ontológica (embora, às vezes, a descubram e mencionem), e pensam quea questão do valor da vida deve decidir-se inteiramente no plano intramundano: se há valores intramundanos, como afetos, saúde, prosperidade econômica e bons vinhos, então, para eles, a vida será valiosa. $N$ ão há aqui qual quer consideração estrutural da vida humana. Com isso, eles se esquecem da diferença que antes fizeram entre o sentido na vida e o sentido da vida, quando se trata da questão do valor. Mas parece perfeitamente inteligível a possibilidade de considerarmosa estrutura (A)-(E) como boa, apesar de infelicidades e frustrações intramundanas, ou como má, apesar de felicidades e realizações intramundanas. Não é o mesmo avaliar a estrutura e avaliar o que acontece dentro dela. A maior felicidade intramundana não será suficiente para dizer que a vida mesma, em seu ser, éboa. Poderia tratar-se de uma felicidade reativa, no registro do "apesar de tudo". Em contrapartida, a maior infelicidade intramundana não será suficiente para dizer que a vida mesma, em seu ser, é má por causa dessa infelicidade. I sso não parece, em absoluto, 
uma questão religiosa ou metafísica, mas uma questão estritamente naturalizada e filosófica.

\section{5 (Des-)VALOR SEN SíVEL DA VIDA HU MANA}

A minha idéia é que podemos dizer, racional e argumentativamente (ou seja, sem introduzir sentimentos, impressões místicas ou convicções religiosas), num tom schopenhaueriano, ${ }^{15}$ que a estrutura da vida humana, em seu ser mesmo, tem um valor sensível negativo, para as maneiras como seres feitos à semelhança dos humanos vivem e padecem os impactos a que são submetidas suas vidas. Pode-se dizer que não é valioso o fato de nascermos mortalmente, de estarmos submetidos ao sofrimento das doenças, ao nosso definhar constante e inexorável e aos sofrimentos vinculados à morte pontual, ao sermos conscientes desses fatos e obrigados a posicionar-nos. Acredito que a totalidade dos seres humanos, quando confrontada autenticamente com a sua condição e sem contrabandos religiosos, admite que a situação estrutural da vida humana não é boa. $E$ creio que seja isso, precisamente, o que leva os seres humanos à construção intramundana de prazeres sensíveis e de valores morais e à constante luta contra a terrível estrutura da vida, como se pretendessem escondêla por trás do que se consegue construir no intramundo. Vejo as vidas humanas como um delicado equilíbrio entre a radical falta de valor da estrutura (do definhar, da queda) e o imenso valor (sensível e moral) que intramundanamente os homens conseguem construir (ou inventar, nos termos de Mackie).

Em geral, julgamos como melhor uma vida de prazeres sensíveis e de gratificações morais do que uma vida cheia de dores, sofrimentos e injustiças. Consideramos melhor uma vida sem estas últimas coisas do que uma vida com elas. U ma vezque a mortalidade estrutural e constitutiva do ser assegura esses elementos - pois não existe vida humana, seja qual for seu conteúdo intramundano, que não contenha sofrimento, dor, conflitos morais, morte, autocons- 
ciência e lidar reativo com a estrutura (A)-(E) -, é coerente que devamos avaliar a estrutura mesma da nossa vida como negativa, como não valiosa do ponto de vista sensível. ${ }^{16} \mathrm{U}$ m ser estruturalmente definhante, cujo definhar gera inevitavelmente sofrimento e dor, não poderá deixar de reconhecer o valor negativo de seu ser mesmo e a necessidade imperiosa de contrabalançar esse valor negativo com o que consiga criar de valioso no intramundo, no plano dos entes, sobre o pano de fundo da negatividade estrutural fundamental. De fato, nossas vidas podem ser vistas como uma luta constante para protelar, mediante as nossas criações intramundanas, a consumação da estrutura mortal do ser, já dada com 0 nascimento. Sustento que a totalidade do valor, sensível e moral, da vida humana é intramundana. Não pode haver valor sensível ou moral na estrutura mesma do definhar, mas apenas naquilo que fazemos com e dentro do definhar.

Ligando novamente sentido com valor, poder-seia dizer que a vida carece de valor estrutural não pelo fato de ela "não ter sentido", mas pelo fato de ser perfeitamente possível construir um sentido para ela - à base, como vimos, de intenções e fins específicos - , sentido que será, entretanto, constantemente corroído e finalmente interrompido, talvez brutalmente, pela mortalidade do ser. A possibilidade, perfeitamente aberta, de construir sentidos na mortalidade do ser constitui o que chamo de valor negativo - ou desvalor - da vida humana em sua estrutura. 0 problema não é, pois, como muitas vezes se acredita, não poder achar-se um sentido para as nossas vidas, mas poder perfeitamente achá-lo, só que sempre nas areias movediças da mortalidade do ser.

6 (Des-)VALOR MORAL DA VIDA HUMANA

O s elementos (A)-(E) da estrutura mortal do ser parecem deixar claro o valor negativo sensível do ser mesmo da vida humana - com seus elementos de definhamento, fragilidade física e mental, doença etc. -, porém não o valor negativo moral do ser da vida. 
Seguindo a distinção kantiana, que eu aceito, o sofrimento sensível não é suficiente para desqualificar o mundo moralmente - lembrese 0 exemplo do doente de gota, na segunda C rítica. Pelo contrário, como Fichte vai sustentar depois, o sofrimento sensível poderia ser - e habitualmente tem sido - um estímulo para o crescimento da moralidade e para o estabelecimento da dignidade humana. $M$ as aqui são relevantes meus argumentos da C rítica de la moral afirmativa, acerca do problema da inabilitação moral provocada regular e gradativamente pelo sofrimento, desde os pequenos sofrimentos cotidianos até as grandes dores a cujo risco estamos desde sempre submetidos. U m ser sensivelmente acuado pelo sofrimento é também um ser em más condições para ser um agente moral ou para ter consideração com seus semelhantes. De fato, ao longo de sua sinistra história, os seres humanos têm se tratado de maneiras desconsideradas até extremos inauditos, impossíveis de serem sequer narrados, tanto nas guerras constantes quanto na tortura da perseguição religiosa e política, nas discriminações raciais e nos extermínios de povos, e na administração cínica e parcial da justiça - que discrimina ricos e pobres, por exemplo - nas sociedades ditas democráticas. Eu não acredito que os homens se tratem de formas desconsideradas devido a algum tipo de "mal radical da natureza humana" ou de "pecado original", mas apenas pela situação factual em que desde sempre já se encontram, dentro da lenta e asfixiante consumação da mortalidade de seu ser. A condição estrutural em que os homens se encontram estreita drasticamente seus espaços de consideração dos interesses de outros. Trata-se de uma situação radical, não de uma essência. Essa situação, embora não mude, poderia ser mudada. É possível pensar em outras coisas que seres como os humanos poderiam fazer com a mortalidade do seu ser. M as, ao longo da história, a desconsideração pelos outros tem sido a solução mágica para o estreitamento dos espaços morais pela penúria e pelo sofrimento, como se o outro fosse o culpado da mortalidade do ser, como se, sendo exterminado, o ser pudesse ser vivido não mortalmente. Como na fábula do Projeto de ética negativa, 
em que vários homens encerrados numa cela pequena acabam se matando uns aos outros, como se fossem os outros os culpados do encerramento. O ra, se é estrutural o sofrimento do definhar mortal, a inabilitação moral, a desconsideração a que os homens têm regularmente se entregado apresenta-se como uma conseqüência regular daquela situação. Dessa forma, um negativo moral fica internamente vinculado à situação estrutural descrita por (A)-(E).

Para a prova do caráter negativo da vida humana em sua estrutura, 0 aspecto moral é relevante, pois não é suficiente mostrar que essa estrutura é dolorosa, mas é necessário mostrar que ela é também moral mente inabilitante, ou seja, má não apenas em sentido sensível, mas também em sentido moral. I sso problematiza não apenas a idéia da felicidade, mas também a idéia de ser digno da felicidade, para usar a terminologia kantiana. Para uma pessoa sensível, um mundo ondenão épossível ser moral deveser tão desagradável quanto um mundo onde não é possível ser feliz. Pode não se entender ab initio o caráter estrutural da inabilitação moral. Depois de tudo se dirá: existem pessoas honestas. M as sustento que se trata sempre, no melhor dos casos, de ações honestas intramundanas, realizadas sobre o pano de fundo de uma impossibilidade estrutural de ser honesto em todas as circunstâncias. Aqui é bom lembrar a articulação ética fundamental (AEF), apresentada na Crítica de la moral afirmativa, a obrigação de levar em conta também os interesses dos outros. Sustento que o estrangulamento dos espaços de ação, por obra da mortalidade do ser - não apenas pelo fato de sermos mortais, mas por sermos segundo a estrutura (A)-(E), no registro do sofrimento, do desgaste etc. -, faz com que todos os humanos transgridam a AEF em algum ponto de seu agir no mundo, às vezes acidentalmente, ou por pusilanimidade, outras vezes, de uma maneira abertamente proposital. Sim, nem todas as pessoas são desonestas. A maioria não tem sequer essa coragem. Muitos são omissos, indiferentes, covardes, tímidos ou coniventes. 0 nazismo não foi erguido apenas pela desonestidade de um grupo, mas também pela omissão, pela indiferença e pela estupidez 
da população e dos intelectuais. Não só de desonestos vive a imoralidade.

As ações humanas devem ser vistas dentro de um ciclo em que ações hon estas e consideradas podem ser feitas num certo ponto desse ciclo, sendo seguidas, em outros pontos, por ações desonestas, desconsideradas ou indiferentese omissas. C ontinuamente passamos da consideração à desconsideração, da indiferença ao carinho, do respeito ao deboche. Isso se torna evidente em Last orders - o filme recente deFred Schepisi - por meio das diferentes atitudes do grupo diante de Jack, o amigo morto. O utra confirmação desse fato está na sinistra cordialidade dos soldados alemães com as senhoras judias que chegavam a Auschwitz. Até os piores carrascos sentem, em determinado momento de seu ciclo de ações, bons sentimentos, vontade de conversar e compreen der as suas vítimas, talvez minutos antes de reiniciar a tortura. C reio que um estudo empírico de ações poderia mostrar esse ponto, contido na intuição kantiana de nunca ter havido, na verdade, uma única ação norteada pela lei moral.

Resumindo: a vida humana mesma pode ser mostrada como sensível e moralmente má em termos perfeitamente naturais - nem teístas nem diabólicos -, enquanto não poderíamos mostrar nãoteisticamente al go como um sentido da vida humana em si mesma. N ão obstante isso, podemos perfeitamente atribuir valores intramundanos às coisas internas à vida, o que habitualmente fazemos, mesmo aceitando o desvalor estrutural - sensível e moral - da vida. No caso do sentido, a construção intramundana era tudo, porque não havia nada como um sentido ou sem-sentido da vida mesma sem recursos teístas -; em contrapartida, no plano do valor, os valores construídos intramundanamente parecem reativos a uma situação negativa inicial. ${ }^{17}$

\section{V ALE A VIDA A PENA DE SER VIVIDA?}

A té aqui percorremos os problemas do sentido e do valor da vida humana. U ma tese pessimista foi formulada sobre o desvalor 
estrutural da vida humana, nos planos sensível e moral. Decorreria daí, automaticamente, uma decisão negativa acerca da questão: "vale ou não a pena viver a vida"? Em 0 mito de Sísifo, C amus assim 0 sugere. ${ }^{18} \mathrm{M}$ as eu não concordo. Enquanto a prova do desvalor estrutural da vida humana me parece perfeitamente objetiva, a questão de decidir-se se vale ou não a pena viver uma vida humana me parece perfeitamente subjetiva, ou melhor, pessoal. Q ualquer vida humana, na minha análise, é um certo tipo de equilíbrio tentado entre o negativo estrutural e os valores sensíveis e morais criados no intramundo. Em algumas vidas, a estrutura negativa poderá privá-las totalmente: a pessoa se suicida, ou pede que a matem, como na eutanásia, ou enlouquece. Em outros casos, os valores intramundanos podem ser extraordinariamente fortes, tão fortes até o ponto de fazer esquecer totalmente a estrutura mortal do ser. E existem muitos casos intermediários. A maioria das pessoas parece estar satisfeita por viver, apesar dos sofrimentos. M as não se descarta a possibilidade de al guém não estar satisfeito de ter surgido (de ter de viver seu definhar), apesar de prazeres e realizações intramundanos. Acredito que essa questão não tenha decisão objetiva. M as isso não deve confundir-se com a descrição da estrutura (A)-(E), que me parece, esta sim, objetiva. A partir do que está aí, as decisões são muitas e variadas, mas há aí um núcleo duro, a partir do qual a variedade de decisões surge.

\section{A Auto-su STENTAÇÃo DA VIDA E OS ARGUMENTOS}

A credito que meus argumentos acerca do sentido e do valor da vida humana sejam corretos. C reio que Schopenhauer esteja certo ao dizer que, se examinássemos a questão do valor da vida apenas com a razão, deveríamos escolher o não-ser. M as nós somos também vontade, pulsão, sexualidade. $\mathrm{N}$ ão vivemos apenas de argumentos. N esse sentido, eu creio que a vida em geral e a vida humana em particular possuam um extraordinário poder de autosustentação, que não é de caráter argumentativo e que nenhum 
argumento é capaz de derrubar. Podemos estar cientes de tudo 0 que é mau na vida e continuar vivendo. Mas isso não deve ser considerado como um argumento em favor do valor da vida. A vida se auto-sustenta, sem argumentos, em seu desvalor. C reio que os argumentos estejam todos a favor do não-ser, do pessimismo e do negativo. M as não é com argumentos que a vida se auto-sustenta. N essa direção, toda a questão do sentido e do valor da vida me parece uma típica questão filosófica. Se assumirmos a postura filosófica diante do mundo, a vida deverá ser julgada pela sua falta de valor estrutural. N esse sentido, como N ietzsche já afirmara, a filosofia é visceralmente niilista. M as se a filosofia mostra a falta de valor da vida, a vida mostra a falta de valor da filosofia. Se a filosofia mostra que a vida não tem valor, a vida mostra que o valor não tem nenhuma vida, que al guém que se coloca a questão do valor da vida já perdeu a vitalidade, pois uma vida exultante não se pergunta pelo seu próprio valor, apenas se consuma. Essa é a linha de $\mathrm{N}$ ietzsche. Eu creio que as duas coisas sejam verdadeiras. Há uma espécie de conflito entre vida e verdade, vida e filosofia. D o ponto de vista da filosofia, a vida está condenada, e vice-versa. Para que 0 desvalor da vida não apareça, para que o "problema da vida" se dissolva, devem-se abandonar os argumentos, ou, como W ittgenstein dizia, deve-se deixar de ser filósofo. Todo o problema do "sentido da vida" mostra a vida vista desde a filosofia. Vendo a filosofia a partir da vida, todo o problema do "sentido da vida" simplesmente se dissolve, não por ser "absurdo" ou "sem sentido" - categorias que a vida não maneja - , mas pelo mesmo ímpeto de rejeição com que o lacrimejar dos olhos expulsa deles um corpo estranho.

ABSTRACT: In this work I maintain that the question for the sense of life and the question for its value are crucially different, even when frequently treated as being exactly the same thing. I hold that the both of them can be clearly answered in as much as they are put in a double dimension usually neglected by analytic philosophers: the sense and value of life itself, and the sense and value of events internal to life. W ithout such a difference in mind the whole question of meaning of life will be rather impoverished.

Key words: Sense of life, value of life, analytic philosophy, moral. 


\section{Notes}

1. É claro quea tese da distinção - não da separação - entre sentido e valor tem chances de se sustentar somente se entendemos esses termos como eu os apresento aqui, enão da maneira como al gum dicionário, ou al gum outro filósofo, como W ittgenstein, por exemplo, os apresentam (veja, neste fascículo, o texto do Prof. Paulo M argutti).

2. A pesar de a literatura falar, em geral, apenas do sentido da vida, parece evidente que todos os trabalhos sobre essa questão, a não ser que se esclareça algo a respeito, referem-se ao sentido da vida humana; de maneira que toda vez que eu falar apenas do sentido (ou do valor) da vida, falarei elipticamente do sentido (ou valor) da vida humana.

3. Klemke (2000), part three: "Q uestioning the question". A gradeço a A gnaldo Cuoco Portugal por ter-me fornecido o livro de Klemke para al guns dos meus confrontos.

4. A gradeço a M arcos Paiva pelas críticas importantes às questões apresentadas nesta seção.

5. 'W hen we ask: 'W hat is the meaning of life?' we want an answer that is more than just an explanation or description of how people behave or how events are arranged or how the world is constituted. We are asking for a justification of our existence" (N ielsen Kai, "Linguistic Philosophy and 'The meaning of life'", in Klemke, op. cit., p. 237). A qui se faz, claramente, a distinção que tento estabelecer.

6. Cf. R. W. H epburn, "Q uestions about the meaning of life", em Klemke, op. cit., p. 269, onde se aponta que as pessoas costumam referir-se a uma vida de sofrimento como pointless e senseless. A qui se confunde claramente o desagradável - 0 desvalor sensível -, queéuma questão de valor, com o absurdo ou ininteligível, queé uma questão de sentido. U ma dor poderia continuar sendo insuportável, ou seja, sem valor sensível, ainda quando alguém, 
talvez a mesma pessoa que a sofresse, conseguisse dar-lhe algum "sentido", ou descobrisse que essa dor teria realmente um sentido. A dor é intensiva, enquanto os sentidos são extensivos. Camus, em 0 mito de Sísifo, dá uma "solução" ao problema do absurdo, ou seja, ao problema do sentido da vida, masnão ao problema do valor da vida. Para melhor tratamento deste, o mito de Prometeu seria mais adequado, pois enquanto Sísifo sofre apenas porque sua vida não tem sentido, Prometeu está sofrendo de dor física insuportável (ver seções 5 e 6 deste trabalho).

7. C f. Paul Edwards, "The meaning and value of life", em Klemke, op. cit., p. 144.

8. Klemke, op. cit., primeira parte.

9. C f. Ayer A. J, "The claims of philosophy", em Klemke, op. cit., p. 226.

10. Cf. Kurt Baier, "The meaning of life", em Klemke, op. cit., p. 120.

11. Idem, p. 128. O utras passagens em que a diferença é feita: Klemke, p. 129, 143, 152, 157.

12. Eu diria que a compreensão ou incompreensão da diferença ontológica éo ponto fulcral de conflito entre filosofias analíticas e continentais, e não apenas na questão do "sentido da vida".

13. C f. Projeto de ética negativa (1989) e C rítica de la moral afirmativa (1996).

14. Devo a Jorge Alam Pereira observações que me levaram a modificar a formulação inicial desta estrutura, em particular no que se refere à característica (E).

15. Só o tom, porque a linha de argumentação é diferente. Em particular, sigo Schopenhauer na sua descrição da condição humana, mas não sou obrigado a segui-lo em tudo, particularmente naquilo que Paulo M argutti chama de "dimensão redentora" da existência, eque envolve elementos místicose religiosos. Eu posso aceitar esses elementos como se fizessem parte de 
formas de vida humana perfeitamente viáveis, mas não como argumentos filosoficamente relevantes para jul gar a questão do valor da vida humana. N esse sentido, concordo com a veemente manifestação de John Searle em A rededescoberta da mente (cap. 4, parágrafo I, p. 134-135). N um futuro número da Philósophos pretendo responder um a um os pontos colocados por M argutti em seu estimulante texto.

16. O u como uma "mercadoria ruim", nos termos de Schopenhauer (cf. Brum, José Thomaz, 0 pessimismo e suas vontades, p. 40).

17. M esmo filósofos tão insuspeitadamente afirmativos quanto Fernando Savater (veja-se, apenas como amostra, seu prefácio a meu livro de 1996) colocam claramente este aspecto "reativo" da invenção de valores a uma situação desvantajosa inicial. Cf: "El ideal ético es, pues, una propuesta activa contra las obras y los fastos de la muerte. $\mathrm{N}$ i salva ni consuela de la muerte; se afirma contra ella, negando el tiempo de que la muerte está hecha" (Fernando Savater, Invitación a la ética, p. 146). O u: "H asta tal punto los valores surgen del afán de perseverar en el ser [...] que sin proyecto de inmortalidad no habría ni ética, ni derecho ni política. [...] lo único que la voluntad humana no quiere jamás es morir; hasta cuando opta por cierto tipo de muerte, lo hace en nombre dela supervivencia radical" (Fernando Savater, É tica como amor propio, p. 20). Não está presente em Savater a idéia da mortalidade como val or negativo - ou desvalor - primordial, mas aqui eu perguntaria: por que toda vida humana fugiria de algo que fosse bom, positivo e desejável?

18. Esta idéia - que eu acho extraordinariamente simplória e pouco sutil (e tal vez até agressiva?) - de que o suicídio deve necessariamente e sem mediações derivar-se, pela via racional, da análise negativa do valor da vida humana também está presente, de maneira atenuada, no texto de $M$ argutti e em objeções de al guns de meus estudantes da pós-graduação da U nB. O cupar-meei dessa questão na minha anunciada réplica. 


\section{Referênaias}

Brum, José Thomaz. 0 pessimismo e suas vontades. Rio de Janeiro: Rocco, 1998.

C abrera, Julio. Projeto de ética negativa. São Paulo: M andacaru, 1989. . Crítica de la moral afirmativa. Barcelona: Gedisa, 1996.

Camus, Albert. El mito de Sísifo. M adrid: Alianza Editorial, 2001. [2a reimpr.].

KLemke, E. D. (Ed.). The meaning of life. 2. ed. New York: O xford U niversity Press, 2000.

Metz, Thaddeus. Recent work on the meaning of life. Ethics, $n$. 112, p. 781-814, 2002.

Savater, Fernando. Invitación a la ética. 4. ed. Barcelona: A nagrama, 1986.

. Ética como amor propio. M adrid: M ondadori, 1988.

SeArLe, John. A redescoberta da mente. São Paulo: Martins Fontes, 1997. 